\section{(A) Check for updates}

Cite this: Dalton Trans., 2018, 47 14491

Received 13th August 2018 Accepted 19th September 2018 DOI: 10.1039/c8dt03312a rsc.li/dalton

\title{
Post-synthetic modification of zirconium metal-organic frameworks by catalyst-free aza-Michael additions $\uparrow$
}

\author{
Harina Amer Hamzah, (D) Tom S. Crickmore, Daniel Rixson (D) and \\ Andrew D. Burrows (D) *
}

\begin{abstract}
The reactions of the zirconium MOF $\left[\mathrm{Zr}_{6} \mathrm{O}_{4}(\mathrm{OH})_{4}\left(\mathrm{bdc}-\mathrm{NH}_{2}\right)_{6}\right]\left(\mathrm{UiO}-66-\mathrm{NH}_{2}\right.$, bdc- $\mathrm{NH}_{2}=2$-amino1,4-benzenedicarboxylate) with the Michael acceptors acrylonitrile $\left(\mathrm{CH}_{2}=\mathrm{CHCN}\right)$, acrylic acid $\left(\mathrm{CH}_{2}=\mathrm{CHCO}_{2} \mathrm{H}\right)$, methyl acrylate $\left(\mathrm{CH}_{2}=\mathrm{CHCO}_{2} \mathrm{Me}\right)$ and methyl vinyl ketone $\left(\mathrm{CH}_{2}=\mathrm{CHC}(\mathrm{O}) \mathrm{Me}\right)$ led to post-synthetic modification of the MOF through $\mathrm{C}-\mathrm{N}$ bond formation without loss of crystallinity. The reactions with acrylonitrile and acrylic acid go to completion, yielding $\left[\mathrm{Zr}_{6} \mathrm{O}_{4}(\mathrm{OH})_{4}\left(\mathrm{bdc}-\mathrm{NHCH}_{2} \mathrm{CH}_{2} \mathrm{CN}\right)_{6}\right]$ (UiO-66-AN, 1) and $\left[\mathrm{Zr}_{6} \mathrm{O}_{4}(\mathrm{OH})_{4}\left(\mathrm{bdc}-\mathrm{NHCH}_{2} \mathrm{CH}_{2} \mathrm{CO}_{2} \mathrm{H}\right)_{6}\right]$ (UiO-66-AA, 2) respectively, whereas those with methyl acrylate and methyl vinyl ketone are incomplete, yielding $\left[\mathrm{Zr}_{6} \mathrm{O}_{4}(\mathrm{OH})_{4}\left(\mathrm{bdc}-\mathrm{NH}_{2}\right)_{0.66}(\mathrm{bdc}-\right.$ $\left.\left.\mathrm{NHCH}_{2} \mathrm{CH}_{2} \mathrm{CO}_{2} \mathrm{Me}\right)_{5.34}\right]$ (UiO-66-MA, 3) and $\left[\mathrm{Zr}_{6} \mathrm{O}_{4}(\mathrm{OH})_{4}\left(\mathrm{bdc}-\mathrm{NH}_{2}\right)_{2.76}\left(\mathrm{bdc}-\mathrm{NHCH}_{2} \mathrm{CH}_{2} \mathrm{C}(\mathrm{O}) \mathrm{Me}\right)_{3.24}\right]$ (UiO-66-MVK, 4), respectively. The acrylonitrile-modified MOF UiO-66-AN undergoes further reaction with sodium azide in the presence of zinc(II) chloride in $n$-butanol to form the tetrazolate-modified MOF $\left[\mathrm{Zr}_{6} \mathrm{O}_{4}(\mathrm{OH})_{4}\left(\mathrm{bdc}-\mathrm{NHCH}_{2} \mathrm{CH}_{2} \mathrm{CN}\right)_{4.74}\left(\mathrm{bdc}-\mathrm{NHCH}_{2} \mathrm{CH}_{2} \mathrm{CN}_{4} \mathrm{H}\right)_{1.26}\right](\mathrm{UiO}-66-\mathrm{TZ}, 5)$.
\end{abstract}

\section{Introduction}

Metal-organic frameworks (MOFs) can be regarded as a new generation of porous materials ${ }^{1}$ and they continue to attract considerable attention for applications as wide-ranging as carbon capture, ${ }^{2}$ catalysis, ${ }^{3}$ drug delivery, ${ }^{4}$ and chemical weapon detoxification. ${ }^{5}$ Much of this interest derives from the enormous diversity of MOF structures, with variation of both the metal centres and organic linkers providing an effectively limitless number of possible materials with different pore sizes and shapes. Of particular interest for many applications is the potential for precise functionalisation of the pore walls, which is possible by using a linker ligand that contains an appropriate functional group capable of projecting into the pores. Unfortunately, many functional groups are intolerant to the synthetic conditions used to prepare MOFs, so direct reaction of a metal salt and the ligand containing the desired functionality often does not yield the anticipated product. Post-synthetic modification ${ }^{6,7}$ has emerged as a powerful tool for circumventing this issue, and in many cases, it provides the only route to including a particular functional group onto the framework of a MOF structure.

Department of Chemistry, University of Bath, Claverton Down, Bath BA2 7AY, UK. E-mail: a.d.burrows@bath.ac.uk

$\dagger$ Electronic supplementary information (ESI) available: Syntheses and characterisation of products. See DOI: 10.1039/c8dt03312a
A wide range of covalent post-synthetic modification reactions have been developed over recent years, including conversion of primary amines into amides, ${ }^{8}$ isocyanates, ${ }^{9}$ ureas, ${ }^{10}$ azides, ${ }^{11} \beta$-amidoketones ${ }^{12}$ and secondary amines, ${ }^{13}$ aldehydes into hydrazones, ${ }^{14}$ azides into triazoles ${ }^{15}$ and bromides into nitriles, ${ }^{16}$ in addition to oxidation, ${ }^{17}$ reduction ${ }^{18}$ and Mannich reactions. ${ }^{19}$ Many of these post-synthetic modification reactions were developed on zinc MOFs, whose limited moisture stability places constraints on the reactions that can be utilised and the applications of the modified MOFs. The more recent extension of post-synthetic modification protocols to moistureand acid-stable MOFs allows the use of reactions that would destroy more sensitive frameworks. Thus, for example, we previously reported that the amino groups in $\left[\mathrm{Cr}_{3} \mathrm{O}(\mathrm{F} / \mathrm{OH})\right.$ $\left.\left(\mathrm{H}_{2} \mathrm{O}\right)_{2}\left(\text { bdc- } \mathrm{NH}_{2}\right)_{3}\right]$ (MIL-101(Cr)- $\mathrm{NH}_{2}$, bdc- $\mathrm{NH}_{2}=$ 2-amino-1,4benzenedicarboxylate) could be transformed into diazonium ions, which could subsequently be converted into halides or azo dyes. ${ }^{20}$ Post-synthetic modifications on derivatives of the water-stable zirconium MOF $\left[\mathrm{Zr}_{6} \mathrm{O}_{4}(\mathrm{OH})_{4}(\mathrm{bdc})_{6}\right](\mathrm{UiO}-66, \mathrm{bdc}=$ 1,4-benzenedicarboxylate) have recently been reviewed by Marshall and Forgan. ${ }^{21}$

We are interested in developing new post-synthetic methods that allow different functional groups to be incorporated into stable MOFs. In this context, aza-Michael reactions provide a potential method of introducing a range of functionalities into MOF structures. The aza-Michael reaction is a conjugate addition in which a nitrogen nucleophile adds to the 
(a)

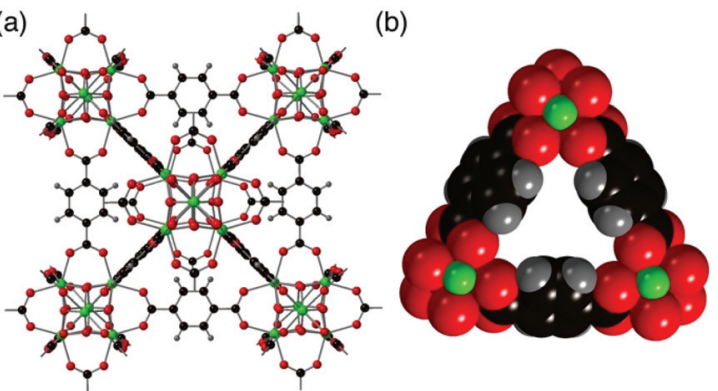

Fig. 1 (a) Part of the UiO-66 structure, with hydrogen atoms on the disordered hydroxide ligands in the $\mathrm{Zr}_{6} \mathrm{O}_{4}(\mathrm{OH})_{4}\left(\mathrm{O}_{2} \mathrm{C}\right)_{6}$ secondary building units omitted for clarity. (b) Space-filling representation of a triangular window in UiO-66. The amino group in UiO-66- $\mathrm{NH}_{2}$ is disordered across the four positions of the benzene ring and has not been observed crystallographically. O, red; C, black; H, grey; Zr, green.

$\beta$-carbon of an electron-deficient alkene. ${ }^{22}$ The reaction is a versatile method for constructing new $\mathrm{C}-\mathrm{N}$ bonds, and it generally requires a Lewis acid catalyst such as $\mathrm{Bi}(\mathrm{OTf})_{3}$ or $\mathrm{SmI}_{2}$ to proceed. ${ }^{23,24}$ More recent studies have shown that the azaMichael reaction can take place without the aid of a catalyst. For example, Li and co-workers demonstrated that azoles react readily with a range of $\beta, \gamma$-unsaturated $\alpha$-keto esters to afford new $\mathrm{C}-\mathrm{N}$ bond adducts, ${ }^{25}$ whereas Legros, Crousse and coworkers reported that aza-Michael additions could progress in polar protic solvents without any promoting agent. ${ }^{26}$ In this report, they demonstrated that the choice of the solvent is crucial in determining the products obtained, with both the mono-adduct and the di-adduct accessible.

Encouraged by the precedence for catalyst-free Michael additions, we sought to assess whether such reactions could be employed in the post-synthetic modification of MOFs. To this end we have investigated the aza-Michael addition reactions between $\left[\mathrm{Zr}_{6} \mathrm{O}_{4}(\mathrm{OH})_{4}\left(\mathrm{bdc}-\mathrm{NH}_{2}\right)_{6}\right] \quad\left(\mathrm{UiO}-66-\mathrm{NH}_{2}\right)$ and acrylonitrile $\left(\mathrm{CH}_{2}=\mathrm{CHCN}\right)$, acrylic acid $\left(\mathrm{CH}_{2}=\mathrm{CHCO}_{2} \mathrm{H}\right)$, methyl acrylate $\left(\mathrm{CH}_{2}=\mathrm{CHCO}_{2} \mathrm{Me}\right)$ and methyl vinyl ketone $\left(\mathrm{CH}_{2}=\mathrm{CHC}(\mathrm{O}) \mathrm{Me}\right)$. UiO-66- $\mathrm{NH}_{2}$ was selected for study based on the high chemical stability of UiO-66 MOFs in different solvents and the relatively large pore apertures present (Fig. 1). ${ }^{27}$ This pore window size is crucial, as a MOF with insufficiently large apertures would not allow for diffusion of the reactants into the framework, which would restrict reactions to the external crystal surfaces. In this context, UiO-66- $\mathrm{NH}_{2}$ has an aperture size of $6.0 \AA$ (ref. 27, 28) which is large enough for diffusion of small reactants into the pores. Furthermore, UiO-66 structures generally contain defects such as missing linkers ${ }^{29-31}$ and, as a consequence, reagents that are larger than the pore windows can, in practice, access reactive sites within the pores.

\section{Results and discussion}

UiO-66- $\mathrm{NH}_{2}$ was synthesised using a previously reported procedure. ${ }^{32}$ The as-synthesised MOF was rinsed and soaked in
$\mathrm{MeOH}$ for 3 days, replacing the solvent with fresh $\mathrm{MeOH}$ every 24 hours. Subsequently, the yellow microcrystalline material was collected via centrifugation and dried under reduced pressure. The reaction between UiO-66- $\mathrm{NH}_{2}$ and acrylonitrile was initially carried out under reflux for $24 \mathrm{~h}$ using a range of solvents. While a small degree of conversion (4-5\%) was observed using the polar protic solvents hexafluoroisopropanol and 2,2,2-trifluoroethanol, the best conversion (38\%) was found using water as the solvent. In all cases, the degree of conversion was obtained from the ${ }^{1} \mathrm{H}$ NMR spectrum of the digested MOF. Most previous work ${ }^{32-35}$ has used hydrofluoric acid to digest UiO-66 and its derivatives. We found that UiO-66- $\mathrm{NH}_{2}$ and its derivatives were readily digested in ammonium fluoride solution, and have used $\mathrm{NH}_{4} \mathrm{~F} / \mathrm{D}_{2} \mathrm{O}$ as a digestion method throughout this work in order to avoid the hazards associated with $\mathrm{HF}$, with DMSO- $d_{6}$ added for ${ }^{1} \mathrm{H}$ NMR analyses. ${ }^{19}$

Lengthening the reaction time from $24 \mathrm{~h}$ to 5 days increased the extent of modification to $50 \%$, though further increase of the reaction time did not lead to higher percentage conversions. However, complete conversion was achieved on leaving the reaction in an autoclave at $120{ }^{\circ} \mathrm{C}$ for 2 days to yield a product with the formula $\left[\mathrm{Zr}_{6} \mathrm{O}_{4}(\mathrm{OH})_{4}(\mathrm{bdc}-\right.$ $\left.\mathrm{NHCH}_{2} \mathrm{CH}_{2} \mathrm{CN}\right)_{6}$ ], UiO-66-AN, 1 (Scheme 1). It is likely that the closed environment created by the autoclave prevents acrylonitrile vapour from being lost from the reaction vessel, and this combined with the higher temperature leads to full conversion.

The ${ }^{1} \mathrm{H}$ NMR spectrum for UiO-66-AN following digestion (Fig. S1 $\dagger$ ) shows triplets at $\delta 2.71 \mathrm{ppm}$ and $\delta 3.42 \mathrm{ppm}$ which correspond to the $\beta$ - and $\alpha$-protons to the secondary nitrogen of $\mathrm{D}_{2}$ bdc- $\mathrm{NHCH}_{2} \mathrm{CH}_{2} \mathrm{CN}$. The resonances at $\delta 6.95$ (dd), 7.05 (d) and 7.65 (d) ppm correspond to the protons from the aromatic ring of $\mathrm{D}_{2}$ bdc- $\mathrm{NHCH}_{2} \mathrm{CH}_{2} \mathrm{CN}$. The addition of a second acrylonitrile molecule into UiO-66-AN to form the di-adduct with bdc- $\mathrm{N}\left(\mathrm{CH}_{2} \mathrm{CH}_{2} \mathrm{CN}\right)_{2}$ substituents was ruled out through comparison of the integrals for the aromatic and aliphatic protons. Furthermore, the negative ion ESI mass spectrum of UiO-66-AN digested in $\mathrm{NH}_{4} \mathrm{~F} / \mathrm{H}_{2} \mathrm{O}$ confirms the presence of the singly deprotonated anion of $\mathrm{H}_{2}$ bdc- $\mathrm{NHCH}_{2} \mathrm{CH}_{2} \mathrm{CN}$ at $\mathrm{m} / \mathrm{z}=$ 233.0561 (predicted $[\mathrm{M}-\mathrm{H}]^{-}=233.0562$ ). The FTIR spectrum for UiO-66-AN (Fig. S2 $\dagger$ ) shows a broad peak at $3364 \mathrm{~cm}^{-1}$

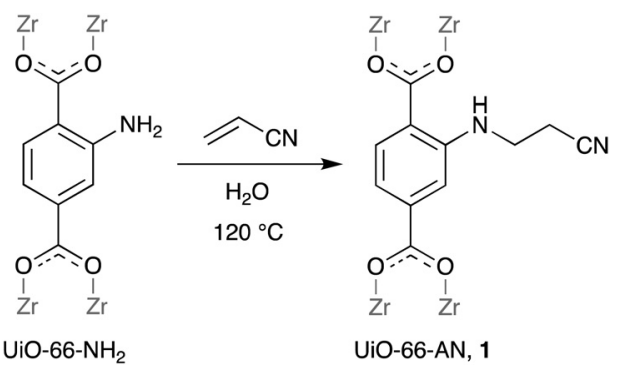

Scheme 1 Post-synthetic modification of $\mathrm{UiO}-66-\mathrm{NH}_{2}$ on reaction with acrylonitrile. 
which corresponds to $\nu(\mathrm{N}-\mathrm{H})$ of the modified framework. The presence of $\nu(\mathrm{C} \equiv \mathrm{N})$ at $2161 \mathrm{~cm}^{-1}$ confirms the presence of the cyanoethyl groups. The high similarity between the powder X-ray diffraction (PXRD) pattern of UiO-66-AN and that of UiO-66- $\mathrm{NH}_{2}$ indicates that the structural integrity of the MOF was retained upon post-synthetic modification (Fig. S3†). This illustrates the robustness of the UiO-66 framework, as neither the post-synthetic modification reaction nor the high temperature employed has any effect on the crystallinity of the MOF. The greater intensity of the peak at $2 \theta 12^{\circ}$ in the PXRD pattern compared with that in the simulated pattern is consistent with previous observations with UiO-66 type MOFs and is related to desolvation, with the calculated pattern based on the activated framework.

Following this optimisation of the reaction conditions, the aza-Michael reaction was repeated using acrylic acid, methyl acrylate, methyl vinyl ketone and vinyl phosphonic acid as Michael acceptors. Successful conversions were observed in the cases of acrylic acid, methyl acrylate and methyl vinyl ketone, as summarised in Scheme 2. Reactions with vinyl phosphonic acid yielded amorphous powders as evidenced by PXRD and were not explored further.

For the reaction with acrylic acid, the ${ }^{1} \mathrm{H}$ NMR spectrum of the $\mathrm{NH}_{4} \mathrm{~F} / \mathrm{D}_{2} \mathrm{O}$-digested product UiO-66-AA (Fig. S4 $\dagger$ ) showed peaks at $\delta 6.94(\mathrm{dd}), 7.09$ (d) and 7.54 (d) ppm, corresponding to the aromatic protons of $\mathrm{D}_{2}$ bdc- $\mathrm{NHCH}_{2} \mathrm{CH}_{2} \mathrm{CO}_{2} \mathrm{D}$. Two sets of triplets at $\delta 2.34$ and $3.23 \mathrm{ppm}$ were also observed and the absence of peaks corresponding to $\mathrm{D}_{2}$ bdc- $\mathrm{NH}_{2}$ confirmed full conversion to $\left[\mathrm{Zr}_{6} \mathrm{O}_{4}(\mathrm{OH})_{4}\left(\text { bdc- } \mathrm{NHCH}_{2} \mathrm{CH}_{2} \mathrm{CO}_{2} \mathrm{H}\right)_{6}\right] 2$. PXRD (Fig. S5 $\dagger$ ) revealed that this product has retained crystallinity and is structurally similar to UiO-66- $\mathrm{NH}_{2}$. Despite the success of these small scale reactions, efforts to scale up the synthesis of 2 proved difficult. ${ }^{1} \mathrm{H}$ NMR spectra carried out on the digested products of larger scale reactions were more complicated than those of the small scale reactions, showing the presence of $\mathrm{D}_{2}$ bdc- $\mathrm{NHCH}_{2} \mathrm{CH}_{2} \mathrm{CO}_{2} \mathrm{D}$ alongside $\mathrm{D}_{2}$ bdc- $\mathrm{N}$ $\left(\mathrm{CH}_{2} \mathrm{CH}_{2} \mathrm{CO}_{2} \mathrm{D}\right)_{2}$ and $\mathrm{D}_{2}$ bdc- $\mathrm{NH}_{2}$, with the presence of the doubly-substituted product confirmed by ESI-MS $(\mathrm{m} / z$ 326.09, $\left.[\mathrm{M}+\mathrm{H}]^{+}\right)$. For this reason, thermal analyses and gas adsorption studies were not carried out on 2.

For the reaction with methyl acrylate, the ${ }^{1} \mathrm{H}$ NMR spectrum of the $\mathrm{NH}_{4} \mathrm{~F} / \mathrm{D}_{2} \mathrm{O}$-digested product (Fig. $\mathrm{S} 6 \dagger$ ) showed peaks at $\delta$

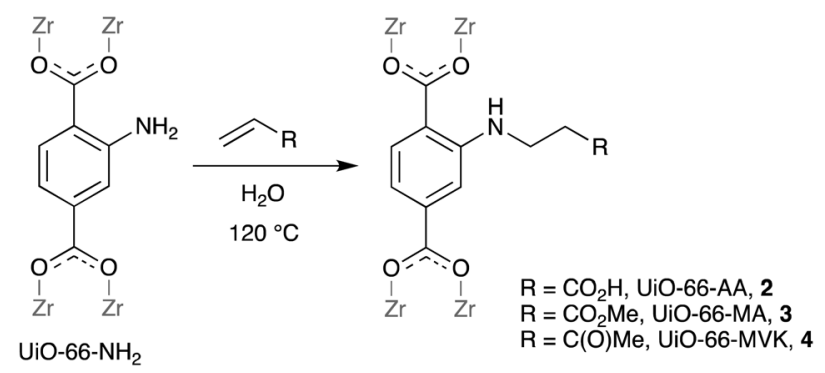

Scheme 2 Post-synthetic modification of UiO-66- $\mathrm{NH}_{2}$ on reaction with acrylic acid, methyl acrylate and methyl vinyl ketone.
6.88 (d), 7.03 (s) and 7.61 (d) ppm, corresponding to the aromatic protons of $\mathrm{D}_{2}$ bdc- $\mathrm{NHCH}_{2} \mathrm{CH}_{2} \mathrm{CO}_{2} \mathrm{Me}$, indicating that the post-synthetic modification was successful. Furthermore, two sets of triplets at $\delta 2.27$ and $3.21 \mathrm{ppm}$ can be seen in the aliphatic region, which correspond to the $\beta$ - and $\alpha$-protons to the secondary nitrogen, respectively. By comparing the integrals of the aromatic protons for $\mathrm{D}_{2}$ bdc- $\mathrm{NHCH}_{2} \mathrm{CH}_{2} \mathrm{CO}_{2} \mathrm{Me}$ with those for $\mathrm{D}_{2}$ bdc- $\mathrm{NH}_{2}$, also present, the degree of conversion can be calculated as $89 \%$. This gives an average formula for UiO-66MA of $\left[\mathrm{Zr}_{6} \mathrm{O}_{4}(\mathrm{OH})_{4}\left(\text { bdc- } \mathrm{NH}_{2}\right)_{0.66}\left(\text { bdc- } \mathrm{NHCH}_{2} \mathrm{CH}_{2} \mathrm{CO}_{2} \mathrm{Me}\right)_{5.34}\right] 3$. The negative ion ESI mass spectrum of $\mathrm{NH}_{4} \mathrm{~F} / \mathrm{H}_{2} \mathrm{O}$-digested UiO-66-MA confirmed the presence of singly deprotonated anion of $\mathrm{H}_{2}$ bdc- $\mathrm{NHCH}_{2} \mathrm{CH}_{2} \mathrm{CO}_{2} \mathrm{Me}$ at $\mathrm{m} / \mathrm{z}=266.0661$ (predicted $\left.[\mathrm{M}-\mathrm{H}]^{-}=266.0665\right)$. The FTIR spectrum showed a weak peak at $3364 \mathrm{~cm}^{-1}$ (Fig. S7 $†$ ), which corresponds to $\nu(\mathrm{N}-\mathrm{H})$. The presence of ester groups on the modified framework was confirmed by observation of $\nu(\mathrm{C}=\mathrm{O})$ at $1712 \mathrm{~cm}^{-1}$. PXRD (Fig. S8 $\dagger$ ) revealed that UiO-66-MA was crystalline, and the similarities between its powder pattern and that for UiO-66- $\mathrm{NH}_{2}$ confirmed that the framework remained intact and retained its crystallinity upon the aza-Michael reaction.

The reaction with methyl vinyl ketone was undertaken using the same conditions as those with acrylonitrile and methyl acrylate. The ${ }^{1} \mathrm{H}$ NMR spectrum of the digested product (Fig. S9†) confirmed that reaction had occurred, with new signals in both the aromatic and aliphatic regions. Specifically, signals at $\delta 6.90$ (d), 7.05 (s) and 7.63 (d) ppm correspond to the aromatic protons in $\mathrm{D}_{2}$ bdc- $\mathrm{NHCH}_{2} \mathrm{CH}_{2} \mathrm{C}(\mathrm{O})$ $\mathrm{Me}$, whereas triplets at $\delta 2.72$ and $3.27 \mathrm{ppm}$ correspond to the $\beta$ - and $\alpha$-protons relative to the secondary nitrogen atom. Based on the aromatic signals for $\mathrm{D}_{2}$ bdc- $\mathrm{NH}_{2}$ and $\mathrm{D}_{2}$ bdc- $\mathrm{NHCH}_{2} \mathrm{CH}_{2} \mathrm{C}(\mathrm{O}) \mathrm{Me}$, it can be deduced that the reaction proceeded with $54 \%$ conversion. The formula for UiO-66-MVK can therefore be expressed as $\left[\mathrm{Zr}_{6} \mathrm{O}_{4}(\mathrm{OH})_{4}\left(\text { bdc- }-\mathrm{NH}_{2}\right)_{2.76}\left(\text { bdc- } \mathrm{NHCH}_{2} \mathrm{CH}_{2} \mathrm{C}(\mathrm{O}) \mathrm{Me}\right)_{3.24}\right]$ 4. The FTIR spectrum of the solid sample shows a broad peak at $3367 \mathrm{~cm}^{-1}$ (Fig. S10†) which corresponds to $\nu(\mathrm{N}-\mathrm{H})$. The presence of ketone functional groups on the modified framework was confirmed by observation of $\nu(\mathrm{C}=\mathrm{O})$ at $1710 \mathrm{~cm}^{-1}$. PXRD (Fig. S11†) revealed that UiO-66-MVK has the same gross structure as UiO-66- $\mathrm{NH}_{2}$, showing that, as with the aza-Michael additions using acrylonitrile, acrylic acid and methyl acrylate, post-synthetic modification does not affect the crystallinity of the MOF.

The results from the post-synthetic aza-Michael reactions are summarised in Table 1. The degree of conversion from primary amine to the aza-Michael product is related to the electron withdrawing power of the acceptor used, with the nitrile group in acrylonitrile being more electron withdrawing than the ester and ketone groups in methyl acrylate and methyl vinyl ketone, respectively.

In order to access whether the nitrile groups in UiO-66-AN can be transformed into other functional groups, further postsynthetic modification reactions were assessed. Initial results suggested that the most promising of these was the reaction of UiO-66-AN with sodium azide in the presence of zinc(II) chlor- 
Table 1 Outcomes of aza-Michael post-synthetic modification reactions carried out on UiO-66- $\mathrm{NH}_{2}$ at $120^{\circ} \mathrm{C}$ for $48 \mathrm{~h}$

\begin{tabular}{lll}
\hline Michael acceptor & \% Conversion & Product \\
\hline $\mathrm{CH}_{2}=\mathrm{CHCN}$ & 100 & {$\left[\mathrm{Zr}_{6} \mathrm{O}_{4}(\mathrm{OH})_{4}\left(\mathrm{bdc}-\mathrm{NHCH}_{2} \mathrm{CH}_{2} \mathrm{CN}\right)_{6}\right] \mathbf{1}(\mathrm{UiO}-66-\mathrm{AN})$} \\
$\mathrm{CH}_{2}=\mathrm{CHCO}_{2} \mathrm{H}$ & $100^{a}$ & {$\left[\mathrm{Zr}_{6} \mathrm{O}_{4}(\mathrm{OH})_{4}\left(\mathrm{bdc}-\mathrm{NHCH}_{2} \mathrm{CH}_{2} \mathrm{CO}_{2} \mathrm{H}\right)_{6}\right] 2(\mathrm{UiO}-66-\mathrm{AA})$} \\
$\mathrm{CH}_{2}=\mathrm{CHCO} \mathrm{CHe}_{2} \mathrm{Me}$ & 89 & $\left[\mathrm{Zr}_{6} \mathrm{O}_{4}(\mathrm{OH})_{4}\left(\mathrm{bdc}-\mathrm{NH}_{2}\right)_{0.66}\left(\mathrm{bdc}-\mathrm{NHCH}_{2} \mathrm{CH} \mathrm{CO}_{2} \mathrm{Me}\right)_{5.34}\right]$ 3 (UiO-66-MA $)$ \\
$\mathrm{CH}_{2}=\mathrm{CHC}(\mathrm{O}) \mathrm{Me}$ & 54 & {$\left[\mathrm{Zr}_{6} \mathrm{O}_{4}(\mathrm{OH})_{4}\left(\mathrm{bdc}-\mathrm{NH}_{2}\right)_{2.76}\left(\mathrm{bdc}-\mathrm{NHCH}_{2} \mathrm{CH} \mathrm{H}_{2} \mathrm{C}(\mathrm{O}) \mathrm{Me}\right)_{3.24}\right] \mathbf{4}(\mathrm{UiO}-66-\mathrm{MVK})$}
\end{tabular}

${ }^{a}$ Small scale reaction.

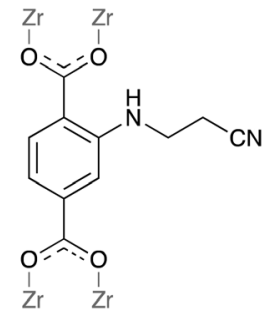

UiO-66-AN

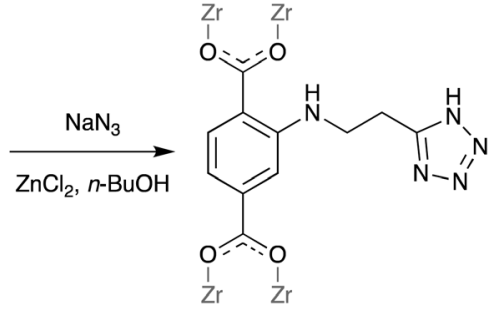

UiO-66-TZ, 5
Scheme 3 Post-synthetic modification of UiO-66-AN on reaction with sodium azide in the presence of zinc(II) chloride and $n$-butanol.

ide, which was anticipated to convert the nitrile groups into tetrazoles. This reaction was found to be very dependent on the solvent used, with no conversion observed using water, ethanol, $n$-propanol, DMF or acetonitrile. In contrast, a reaction was observed when $n$-butanol was used as the solvent (Scheme 3).

The successful conversion of nitrile groups to tetrazoles was confirmed by ${ }^{1} \mathrm{H}$ NMR spectroscopy of the digested product (Fig. S12 $\dagger$ ). New sets of peaks ( $\delta 6.92 \mathrm{~d}, 7.08 \mathrm{~s}$ and $7.61 \mathrm{~d} \mathrm{ppm})$ were observed in the aromatic region, in addition to the peaks which correspond to the aromatic protons of $\mathrm{D}_{2}$ bdc$\mathrm{NHCH}_{2} \mathrm{CH}_{2} \mathrm{CN}$. The new peaks correspond to the protons from the benzene ring of $\mathrm{D}_{2}$ bdc- $\mathrm{NHCH}_{2} \mathrm{CH}_{2} \mathrm{CN}_{4} \mathrm{H}$. A triplet due to the $\beta$-protons to the secondary nitrogen of $\mathrm{D}_{2}$ bdc$\mathrm{NHCH}_{2} \mathrm{CH}_{2} \mathrm{CN}_{4} \mathrm{H}$ is clearly visible at $\delta 3.0 \mathrm{ppm}$, though the triplet of the neighbouring $\alpha$-protons is only partly visible due to overlapping with the more dominant triplet resulting from $\mathrm{D}_{2}$ bdc- $\mathrm{NHCH}_{2} \mathrm{CH}_{2} \mathrm{CN}$. The percentage conversion from nitrile to tetrazole was estimated on the basis of the integrals to be approximately $21 \%$, which gives an formula for UiO-66-TZ as $\left[\mathrm{Zr}_{6} \mathrm{O}_{4}(\mathrm{OH})_{4}\left(\text { bdc- } \mathrm{NHCH}_{2} \mathrm{CH}_{2} \mathrm{CN}\right)_{4.74}\left(\text { bdc- } \mathrm{NHCH}_{2} \mathrm{CH}_{2} \mathrm{CN}_{4} \mathrm{H}\right)_{1.26}\right]$ 5. The negative ion ESI mass spectrum of the digested product confirmed the singly deprotonated anion of $\mathrm{H}_{2}$ bdc$\mathrm{NHCH}_{2} \mathrm{CH}_{2} \mathrm{CN}_{4} \mathrm{H}$ at $m / z=276.0727$ (predicted $[\mathrm{M}-\mathrm{H}]^{-}=$ 276.0733).

In order to investigate the structural integrity of the PSM product, PXRD was carried out on the solid sample UiO-66-TZ. The sample was extensively rinsed with $n$ - $\mathrm{BuOH}$ prior to the PXRD measurement and the pattern of the $n$-BuOH-rinsed sample shows additional peaks at $2 \theta 31.5^{\circ}, 34.5^{\circ}, 36.0^{\circ}$ and $47.5^{\circ}$ in addition to those corresponding to the UiO-66 framework (Fig. S13†). These additional peaks do not derive from unreacted reagents, and they were removed by washing the sample with water. Reactions were undertaken using different times and catalyst loadings, but conversion could not be raised above $21 \%$. This is likely to be a consequence of pore blocking by the relatively large ethyltetrazole groups, which is consistent with the nitrogen adsorption data (vide infra).

The thermal stability of the post-synthetically modified products $\mathbf{1}$ and 3-5 was assessed by thermogravimetric analysis (TGA) (Fig. S14 $\dagger$ ). The samples were rinsed with water prior to the TGA measurements. An initial mass loss of $2-17 \%$ was seen in all cases between 50 and $120{ }^{\circ} \mathrm{C}$. This can be attributed to the loss of included water molecules, and the different amounts reflect the remaining pore space following the modification reactions. A second small $(\sim 3 \%)$ and gradual mass loss $\left(120{ }^{\circ} \mathrm{C}-440{ }^{\circ} \mathrm{C}\right)$ may be attributed to residual DMF solvent in the pores and/or the dehydroxylation of the $\mathrm{Zr}_{6} \mathrm{O}_{4}(\mathrm{OH})_{4}$ nodes. The UiO-66 series of MOFs are known to undergo complete dehydroxylation reactions below $300{ }^{\circ} \mathrm{C} .{ }^{34}$ Normally, a plateau region in a TGA profile represents the range of temperature that can be used to produce the activated form of a MOF. Due to the gradual mass loss in the $120^{\circ} \mathrm{C}-$ $440{ }^{\circ} \mathrm{C}$ region, $120{ }^{\circ} \mathrm{C}$ was chosen as the activation temperature, which is consistent with that used in previous studies on UiO-66 derivatives. ${ }^{36-38}$ The mass loss above $440{ }^{\circ} \mathrm{C}$ corresponds to decomposition of the framework, and is similar to previous reports for UiO-66- $\mathrm{NH}_{2}$ and related MOFs. ${ }^{32,39}$ These results implies that post-synthetic modification does not alter the thermal stability of UiO-66- $\mathrm{NH}_{2}$.

In order to investigate the porosity of the products, $\mathrm{N}_{2}$ adsorption measurements were carried out on $\mathbf{1}$ and 3-5 at $77 \mathrm{~K}$. Prior to the measurements, the samples were activated at $120{ }^{\circ} \mathrm{C}$ for $12 \mathrm{~h} .{ }^{1} \mathrm{H}$ NMR analysis of the digested activated samples confirmed that no solvent molecules were present upon activation. Furthermore, the PXRD patterns of the activated samples were similar to those prior to activation, indicating that the activation conditions did not alter the crystallinity of the MOFs. The $\mathrm{N}_{2}$ adsorption isotherms for UiO-66- $\mathrm{NH}_{2}$ and $\mathbf{1}$ and 3-5 are shown in Fig. 2, and the calculated BET surface areas for these MOFs are given in Table 2.

The BET surface area for UiO-66- $\mathrm{NH}_{2}$ obtained in this work is similar to values reported in the literature for this material, which range from 778 to $1293 \mathrm{~m}^{2} \mathrm{~g}^{-1} \cdot{ }^{32,39-42}$ The derivatives $\mathbf{1}$, 3 and 4 exhibited Type I isotherms with each product showing a lower degree of porosity than UiO-66- $\mathrm{NH}_{2}$, which is consistent with the mass increase caused by the tag groups in the pores which also reduce the space available for guest inclusion. The percentage conversion of the post-synthetic 


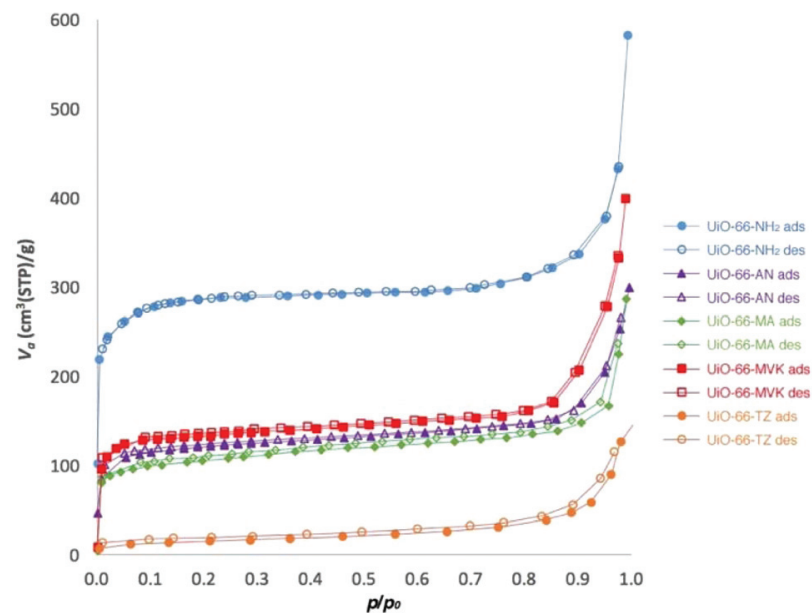

Fig. 2 Adsorption and desorption of $\mathrm{N}_{2}$ by 1 and 3-5 at $77 \mathrm{~K}$ in comparison to $\mathrm{UiO}-66-\mathrm{NH}_{2}$.

Table 2 BET surface areas calculated for UiO- $66-\mathrm{NH}_{2}$ and compounds 1 and 3-5

\begin{tabular}{lc}
\hline Compound & $S_{\text {BET }}\left(\mathrm{m}^{2} \mathrm{~g}^{-1}\right)$ \\
\hline$\left[\mathrm{Zr}_{6} \mathrm{O}_{4}(\mathrm{OH})_{4}\left(\mathrm{bdc}-\mathrm{NH}_{2}\right)_{6}\right]$, UiO-66- $\mathrm{NH}_{2}$ & 1041 \\
UiO-66-AN, 1 & 452 \\
UiO-66-MA, 3 & 392 \\
UiO-66-MVK, 4 & 527 \\
UiO-66-TZ, 5 & 52
\end{tabular}

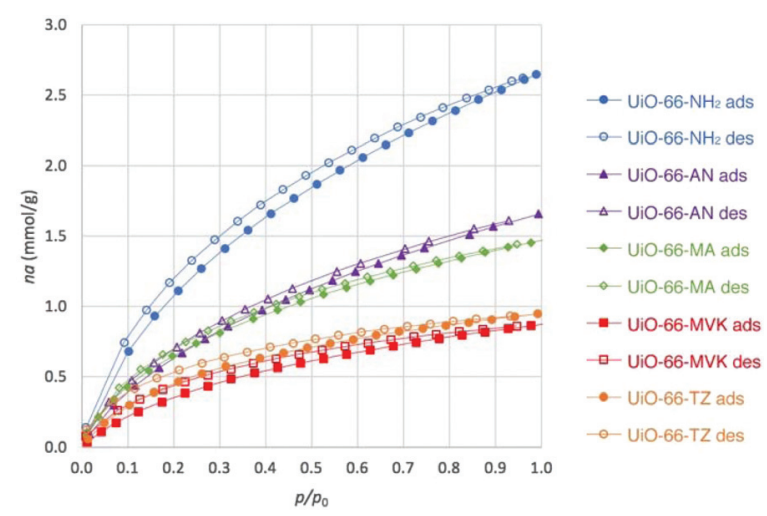

Fig. 3 Adsorption and desorption of $\mathrm{CO}_{2}$ by 1 and $3-5$ at $273 \mathrm{~K}$ in comparison to UiO-66- $\mathrm{NH}_{2}$.

modification reaction also has an impact on the BET surface area and, in general, the higher the percentage conversion, the lower the surface area observed. This accounts for the higher value of $S_{\mathrm{BET}}$ for $\mathbf{4}$ in comparison to $\mathbf{1}$ and $\mathbf{3}$. The effect of pore blocking with large introduced substituents is especially apparent in the essentially non-porous nature of $\mathbf{5}$, which shows a Type II isotherm.

The $\mathrm{CO}_{2}$ isotherms of $\mathbf{1}$ and $\mathbf{3 - 5}$ at $273 \mathrm{~K}$ were also recorded, and are shown in Fig. 3. The $\mathrm{CO}_{2}$ uptakes are lower than that for UiO-66- $\mathrm{NH}_{2}$, which is likely to be related to the pore blocking effect of the tag groups as this limits diffusion of $\mathrm{CO}_{2}$ molecules into the pores. Furthermore, the absence of the primary amine group in the pores may contribute to the lower $\mathrm{CO}_{2}$ uptake. It is notable than the $\mathrm{CO}_{2}$ uptake for $\mathbf{1}$ is higher than that for 3 . This is likely to be due to the relative sizes of the tag groups. Unexpectedly, the $\mathrm{CO}_{2}$ loading of $\mathbf{5}$ is somewhat higher than that for $\mathbf{4}$ despite the former being non-porous to nitrogen. One possible reasoning for this observation is the strong interaction of $\mathrm{CO}_{2}$ molecules with the tetrazole moieties. MOFs with nitrogen-rich environments such as those with tetrazole- and triazole-functionalities have been previously reported to have high affinity towards $\mathrm{CO}_{2},{ }^{43,44}$ and in the case of $\mathbf{5}$ much of this may occur on external surfaces.

\section{Conclusions}

A new versatile, single-step post-synthetic modification reaction for MOFs has been developed. In this process, the primary amino group in UiO-66- $\mathrm{NH}_{2}$ is converted into a range of secondary amines bearing different functional groups via a catalyst-free aza-Michael addition. The reaction was achieved by reacting UiO-66- $\mathrm{NH}_{2}$ with four different alkenes containing electron withdrawing groups, $\mathrm{CH}_{2}=\mathrm{CHR}\left(\mathrm{R}=\mathrm{CN}, \mathrm{CO}_{2} \mathrm{H}\right.$, $\left.\mathrm{CO}_{2} \mathrm{CH}_{3}, \mathrm{C}(\mathrm{O}) \mathrm{CH}_{3}\right)$. The degrees of conversion were governed by the strength of the electron withdrawing groups attached to the alkenes with the stronger electron withdrawing groups leading to higher conversion. Following optimisation, the highest conversion $(100 \%)$ was achieved whilst using either acrylonitrile or acrylic acid, with incomplete reactions for methyl acrylate (89\%) and methyl vinyl ketone (54\%). A second post-synthetic modification was successfully performed on UiO-66-AN in which the MOF was treated with $\mathrm{NaN}_{3}$ and $\mathrm{ZnCl}_{2}$ catalyst in $n$ - $\mathrm{BuOH}$. This reaction resulted in the partial conversion of the nitrile groups into tetrazoles.

We anticipate that the aza-Michael process described is likely to be readily extended to other MOF systems that possess high stability towards $\mathrm{H}_{2} \mathrm{O}$ and alcohols. Current work is seeking to investigate this in addition to expanding the range of alkenes that can be used as Michael acceptors in this process. Furthermore, we are studying additional post-synthetic modification reactions on UiO-66-AN and investigating the acid behaviour of UiO-66-AA.

\section{Conflicts of interest}

There are no conflicts to declare.

\section{Acknowledgements}

The University of Bath and Majlis Amanah Rakyat (MARA) are thanked for a PhD studentship (to HAH). 


\section{Notes and references}

1 H. Furukawa, K. E. Cordova, M. O’Keeffe and O. M. Yaghi, Science, 2013, 341, 1230444.

2 J. Yu, L.-H. Xie, J.-R. Li, Y. Ma, J. M. Seminario and P. B. Balbuena, Chem. Rev., 2017, 117, 9674.

3 L. Zhu, X.-Q. Liu, H.-L. Jiang and L.-B. Sun, Chem. Rev., 2017, 117, 8129.

4 P. Horcajada, R. Gref, T. Baati, P. K. Allan, G. Maurin, P. Couvreur, G. Férey, R. E. Morris and C. Serre, Chem. Rev., 2012, 112, 1232.

5 N. S. Bobbitt, M. L. Mendonca, A. J. Howarth, T. Islamoglu, J. T. Hupp, O. K. Farha and R. Q. Snurr, Chem. Soc. Rev., 2017, 46, 3357.

6 S. M. Cohen, Chem. Rev., 2012, 112, 970.

7 A. D. Burrows, in Postsynthetic Modification of Metal-Organic Frameworks in Metal-Organic Framework Materials, ed. L. R. MacGillivray and C. M. Lukehart, Wiley, 2014, p. 195.

8 K. K. Tanabe, Z. Wang and S. M. Cohen, J. Am. Chem. Soc., 2008, 130, 8508.

9 C. Volkringer and S. M. Cohen, Angew. Chem., Int. Ed., 2010, 49, 4644.

10 E. Dugan, Z. Wang, M. Okamura, A. Medina and S. M. Cohen, Chem. Commun., 2008, 3366.

11 M. Savonnet, D. Bazer-Bachi, N. Bats, J. Perez-Pellitero, E. Jeanneau, V. Lecocq, C. Pinel and D. Farrusseng, J. Am. Chem. Soc., 2010, 132, 4518.

12 W. J. Gee, L. K. Cadman, H. Amer Hamzah, M. F. Mahon, P. R. Raithby and A. D. Burrows, Inorg. Chem., 2016, 55, 10839.

13 A. D. Burrows and L. L. Keenan, CrystEngComm, 2012, 14, 4112.

14 A. D. Burrows, C. G. Frost, M. F. Mahon and C. Richardson, Angew. Chem., Int. Ed., 2008, 47, 8482.

15 Y. Goto, H. Sato, S. Shinkai and K. Sada, J. Am. Chem. Soc., 2008, 130, 14354.

16 M. Kim, S. J. Garibay and S. M. Cohen, Inorg. Chem., 2011, 50, 729.

17 A. D. Burrows, C. G. Frost, M. F. Mahon and C. Richardson, Chem. Commun., 2009, 4218.

18 W. Morris, C. J. Doonan, H. Furukawa, R. Banerjee and O. M. Yaghi, J. Am. Chem. Soc., 2008, 130, 12626.

19 H. Amer Hamzah, W. J. Gee, P. R. Raithby, S. J. Teat, M. F. Mahon and A. D. Burrows, Chem. - Eur. J., 2018, 24, 11094.

20 D. Jiang, L. L. Keenan, A. D. Burrows and K. J. Edler, Chem. Commun., 2012, 48, 12053.

21 R. J. Marshall and R. S. Forgan, Eur. J. Inorg. Chem., 2016, 2016, 4310.

22 J. L. Vicario, D. Badía, L. Carrillo, J. Etxebarria, E. Reyes and N. Ruiz, Org. Prep. Proced. Int., 2005, 37, 513.
23 R. Varala, M. M. Alam and S. R. Adapa, Synlett, 2003, 720.

24 I. Reboule, R. Gil and J. Collin, Tetrahedron Lett., 2005, 46, 7761.

25 J. Wang, P.-F. Li, S. H. Chan, A. S. C. Chan and F. Y. Kwong, Tetrahedron Lett., 2012, 53, 2887.

26 K. De, J. Legros, B. Crousse and D. Bonnet-Delpon, J. Org. Chem., 2009, 74, 6260.

27 J. H. Cavka, S. Jakobsen, U. Olsbye, N. Guillou, C. Lamberti, S. Bordiga and K. P. Lillerud, J. Am. Chem. Soc., 2008, 130, 13850.

28 Q. Yang, H. Jobic, F. Salles, D. Kolokolov, V. Guillerm, C. Serre and G. Maurin, Chem. - Eur. J., 2011, 17, 8882.

29 C. A. Trickett, K. J. Gagnon, S. Lee, F. Gándara, H.-B. Bürgi and O. M. Yaghi, Angew. Chem., Int. Ed., 2015, 54, 11162.

30 C. L. Hobday, R. J. Marshall, C. F. Murphie, J. Sotelo, T. Richards, D. R. Allan, T. Düren, F.-X. Coudert, R. S. Forgan, C. A. Morrison, S. A. Moggach and T. D. Bennett, Angew. Chem., Int. Ed., 2016, 55, 2401.

31 S. Øien, D. Wragg, H. Reinsch, S. Svelle, S. Bordiga, C. Lamberti and K. P. Lillerud, Cryst. Growth Des., 2014, 14, 5370 .

32 S. J. Garibay and S. M. Cohen, Chem. Commun., 2010, 46, 7700.

33 M. Kandiah, S. Usseglio, S. Svelle, U. Olsbye, K. P. Lillerud and M. Tilset, J. Mater. Chem., 2010, 20, 9848.

34 R. Ameloot, M. Aubrey, B. M. Wiers, A. P. Gómora-Figueroa, S. N. Patel, N. P. Balsara and J. R. Long, Chem. - Eur. J., 2013, 19, 5533.

35 C. O. Audu, H. G. T. Nguyen, C.-Y. Chang, M. J. Katz, L. Mao, O. K. Farha, J. T. Hupp and S. T. Nguyen, Chem. Sci., 2016, 7, 6492.

36 Z. Hu, K. Zhang, M. Zhang, Z. Guo, J. Jiang and D. Zhao, ChemSusChem, 2014, 7, 2791.

37 A. Kronast, S. Eckstein, P. T. Altenbuchner, K. Hindelang, S. I. Vagin and B. Rieger, Chem. - Eur. J., 2016, 22, 12800.

38 C. Wang, X. Liu, J. P. Chen and K. Li, Sci. Rep., 2015, 5, 16613.

39 S. M. Chavan, G. C. Shearer, S. Svelle, U. Olsbye, F. Bonino, J. Ethiraj, K. P. Lillerud and S. Bordiga, Inorg. Chem., 2014, 53, 9509.

40 D. Sun, Y. Fu, W. Liu, L. Ye, D. Wang, L. Yang, X. Fu and Z. Li, Chem. - Eur. J., 2013, 19, 14279.

41 J. B. DeCoste, M. A. Browe, G. W. Wagner, J. A. Rossin and G. W. Peterson, Chem. Commun., 2015, 51, 12474.

42 H. Saleem, U. Rafique and R. P. Davies, Microporous Mesoporous Mater., 2016, 221, 238.

43 D.-M. Chen, J.-Y. Tian, M. Chen, C.-S. Liu and M. Du, ACS Appl. Mater. Interfaces, 2016, 8, 18043.

44 S. Seth, G. Savitha and J. N. Moorthy, Inorg. Chem., 2015, 54, 6829. 